\title{
Surgeon's Dilemma in the Management of Unicystic Ameloblastoma in A Pediatric Patient
}

Yashwanth Yadav B ${ }^{1}$, Krishna Kishore $\mathrm{P}^{2}$, Shwetang Goswami ${ }^{3}$, Naseer Mohammed ${ }^{4}$

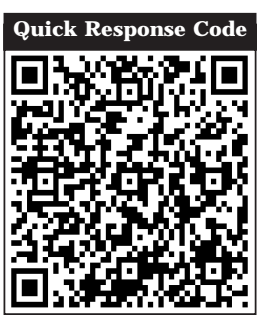

doi: $10.5866 / 2014.621574$

${ }^{1 \& 3}$ Senior Lecturer

${ }^{2 \& 4}$ Post Graduate Student

Department of Oral and maxillofacial surgery,

Kamineni Institute of Dental Sciences

Narketpally, Nalgonda (Dist), Telangana - 508254

\section{Article Info:}

Received: J anuary 13, 2014

Review Completed: February 10, 2014

Accepted: March 11, 2014

Available Online: J uly, 2014 (www.nacd.in)

(C) NAD, 2014 - All rights reserved

\section{Email for correspondence:}

dryash2204@gmail.com

\begin{abstract}
:
Ameloblastomas are benign asymptomatic intraosseous lesions that affect the bones of the maxillomandibular complex, interfering both in function and facial esthetic appearance. Unicystic amel oblastoma has become established as a distinct clinicopathological entity on the general basis of its unicystic radiographic appearance, histologic findings, association with an unerupted tooth, occurrence in the mandible of younger patients, and a recurrence rate after conservative surgical treatment lower than that of its conventional counterpart. Surgical management of amel obl astoma has been a controversial subject. Numerous excellent reviews have addressed this topic. The debate stems from confusion in the literature regarding histologic type of the tumor and from lack of standardization of definitions for "conservative" and "radical" surgical approaches. In this paper we emphasize the importance of enucleation with chemical cauterization followed by decompression as a surgical modality for the management of unicystic ameloblastoma in a pediatric patient.
\end{abstract}

Key words: Unicystic amel oblastoma, conservative, enudeation

\section{INTRODUCTION:}

Unicystic ameloblastoma, described by Robinson and Martinez in 1977, is one of three clinical variants of ameloblastoma, the other two being the more common intraosseous solid or multicystic (conventional) ameloblastoma, and the rarely encountered peripheral ameloblastoma. ${ }^{1}$ Unicystic ameloblastoma has become established as a distinct clinicopathological entity on the general basis of its unicystic radiographic appearance, histologic findings, association with an unerupted tooth, occurrence in the mandible of younger patients, and a recurrence rate after conservative surgical treatment lower than that of its conventional counterpart. ${ }^{2}$

Ackermann et al in 1988 reclassified unicystic amel oblastoma into three types with prognostic and therapeutic implications. ${ }^{3}$ Despite its benign

\section{Indian Journal of Dental Advancements} Journal homepage: www. nacd. in 
histological appearance, amel oblastoma is clinically persistent, disfiguring and can kill from invasion of vital structures, super-infection, recurrence or distant metastases.

Ameloblastoma can occur at any age, but most cases are seen between the 3rd and 5th decades. They are predominantly seen in the middle age group. However, these tumors are also known to occur in children (8.7\% to $15.0 \%$ ). The tumour does not show a sexual predilection. Approximately $85 \%$ of amel oblastomas arise in the mandible, especially in the molar-ramus region, and present radiographically as a multilocular or unilocular radiolucency. Ameloblastomas have been classified histologically into solid/multicystic, extraosseous/ peripheral, desmoplastic, and unicystic variants. ${ }^{4}$

Treatment of mandibular ameloblastomas includes conservative measures such as marsupialization, enucleation and curettage; and radical treatments such as disarticulation, or marginal and segmental resection. ${ }^{5}$

The debate stems from confusion in the literature regarding histologic type of the tumor and from lack of standardization of definitions for "conservative" and "radical" surgical approaches 5 . In this paper we emphasize the importance of decompression followed by enucleation as a surgical modality for the management of unicystic ameloblastoma in a pediatric patient.

\section{CASE REPORT:}

A 10 years old female reported to our department complaining of swelling on theright side of the face since two months (Figure 1). Child was not comfortable with swelling because of unaesthetics as it was identified by the child ten days back. Extra oral examination revealed facial asymmetry on right side of face, the swelling was oval shaped, measuring about $2 \times 1 \mathrm{~cm}$ extending anteriorly $2 \mathrm{~cm}$ from the right ear lobe to $2 \mathrm{~cm}$ behind the right corner of the mouth (Figure 2). Intra oral examination revealed obliteration of vestibule in relation to 46 and 85.

Orthopantamogram (OPG) revealed radiolucency measuring about $4 \times 2 \mathrm{~cm}$. The lesion extending from distal aspect of right deciduous $2^{\text {nd }}$ molar to the inferior border, posteriorly upto the ramus of the mandible leaving one $\mathrm{cm}$ healthy bone behind with a displaced and impacted 47 (Figure 3). After the clinical and radiological examination, incisional biopsy was performed. The histopathological report was suggestive of unicystic ameloblastoma. It showed cystic lining with columnar basal cells, nucleus palisading with polarization and hyperchromatism, cytoplasmic vacuolization with intercellular spacing. Strands of odontogenic epithelium were seen extending into the connective tissue from the lining and producing plexiform pattern with stellate reticulum liketissue between the strands (Figure 4).

Considering the age of the patient and size of thelesion a conservative management was planned. Decompression was carried for 4 months with regular chlorhexidinedressings and monitored twice weekly. Periodic OPG's were taken, after 4 months radiographic assessment showed a reduction in the size of lesion by half of theinitial size. So enucleation was done under LA (Figure 5 and 6). Post operatively patient was asymptomatic (Figure 7). Neurological function was maintained. A series of radiographic examination was done for duration of one year which showed complete development of bone and good healing noted (Figure 8).

\section{DISCUSSION:}

The treatment of choice and the surgical management of mandibular ameloblastomas still remain controversial, and it is not easy to choose from the different approaches that have been proposed. ${ }^{5}$ In the literature, recurrence after conservative (non-resection) treatment of conventional amel oblastoma ranges from 50 to $90 \%{ }^{6}$ But in the present case there had being no signs of recurrence what so ever it was after a follow up of 1year.

Extensive resections have been used to treat solid ameloblastomas to prevent possible recurrences. However, these surgeries are invariably associated with serious problems for the patient, such as masticatory dysfunction, mutilation, facial deformity, and abnormal mandibular movements. The rate of recurrence is a crucial factor for coherent planning, but other aspects are also important and must be considered in the therapeutic approach, including emphasizing morbidity and the patient's quality of life. ${ }^{7}$ 


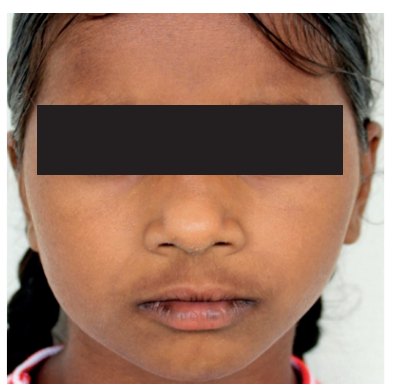

Figure 1: Patient complains of the swelling and discomfort on the right side of face since 2 months.

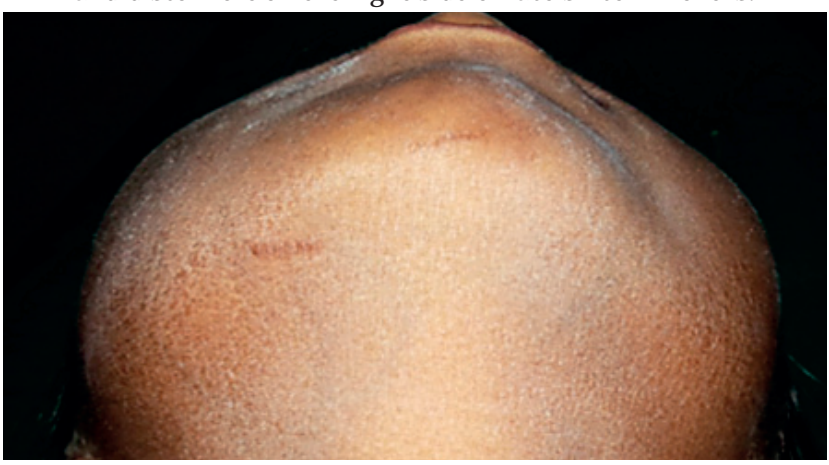

Figure 2: Worms view showing diffuse swelling on the right side of the jaw.

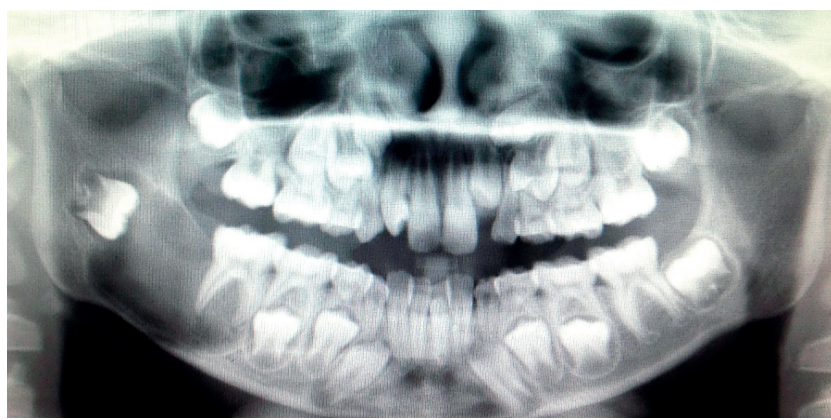

Figure 3: Orthopantamogram (OPG) revealed radiolucency measuring about $4 \times 2 \mathrm{~cm}$. The lesion extending from distal aspect of right deciduous 2 nd molar to the inferior border, posteriorly upto the ramus of the mandible leaving one $\mathrm{cm}$ healthy bone behind with a displaced and impacted 47.

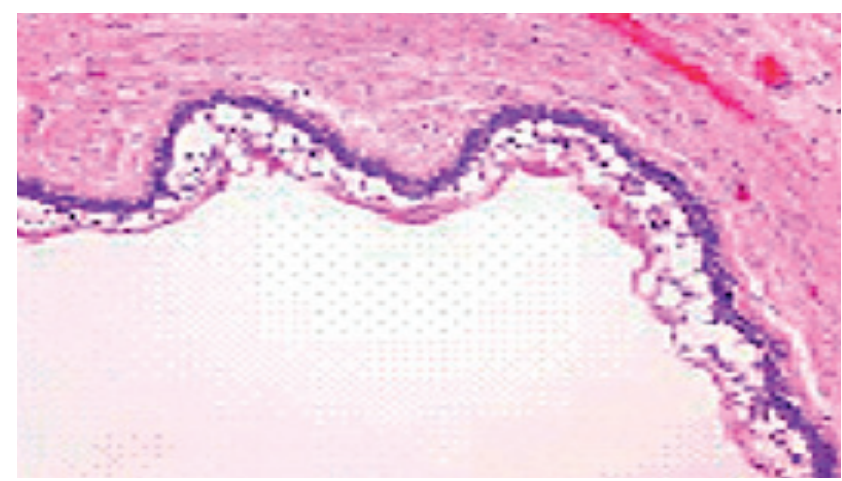

Figure 4: $\mathrm{H}$ and $\mathrm{E}$ section shows epithelial lining with loosely disposed cells resembling stellate reticulum. Basal layer can be seen showing a hyperchromatic and polarized basal cells.

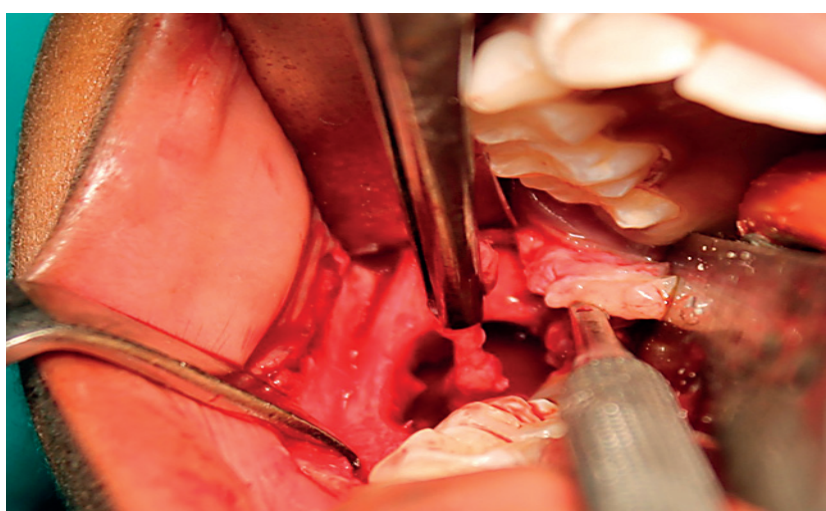

Figure 5: Enucleation done under LA

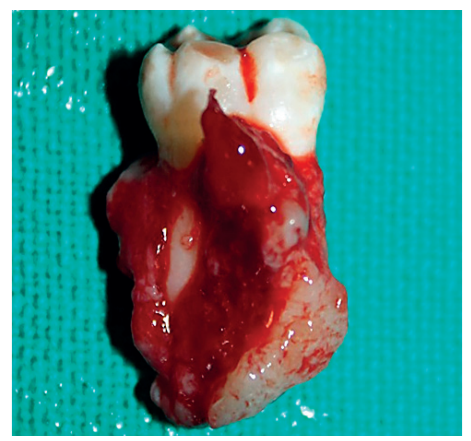

Figure 6: Extraction of 46 done

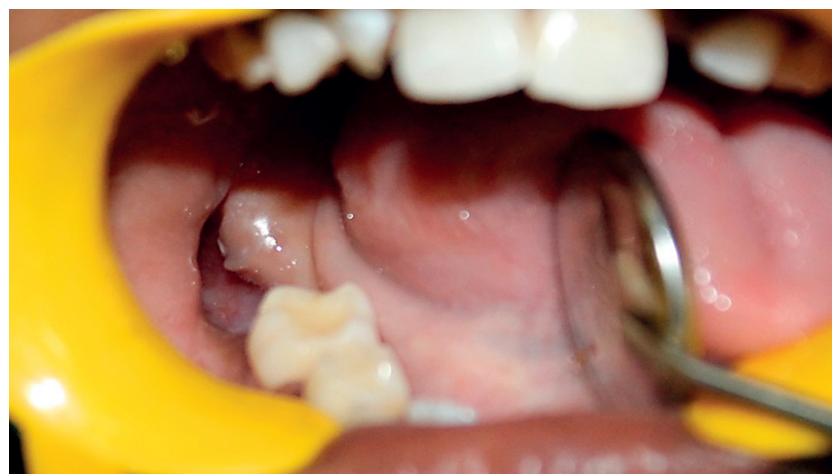

Figure 7: Intraoral images of the patient with no evidence of recurrence and no swelling noted 1 year post operatively.

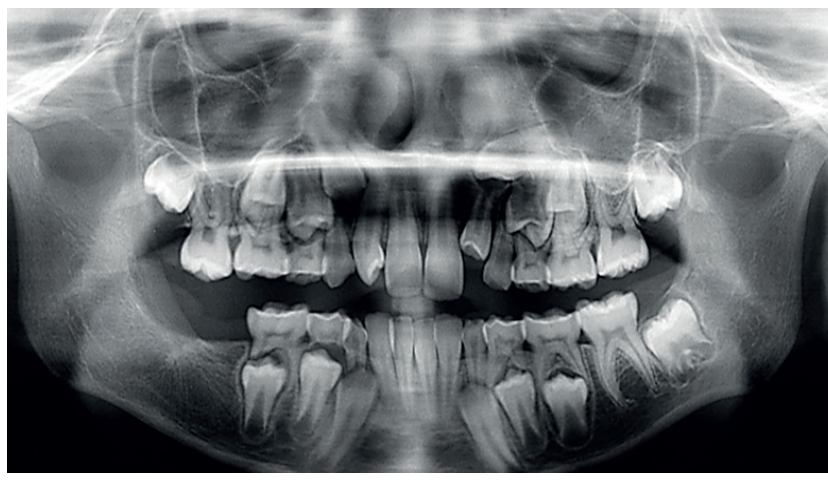

Figure 8: 1 year post operative OPG showing complete development of bone and good healing noted. 
A unicystic intraosseous ameloblastoma deserves separate consideration, because of its distinct clinical, radiographic, and histopathologic characteristics. Three histopathologic variants of unicystic amel oblastoma have been described. In the first type, luminal unicystic ameloblastoma, the tumor is confined to the luminal surface of the cyst, and the lesion has a fibrous cyst wall, with a lining consisting partially or totally of ameloblastic epithelium. In the second variant, intraluminal unicystic ameloblastoma, at least 1 nodule of the ameloblastoma projects from the cystic lining into the lumen of the cyst. These nodules can be relatively small or largely fill the cystic lumen. In the third type, mural unicystic ameloblastoma, the fibrous wall of the cyst is infiltrated by a typical follicular or plexiform ameloblastoma. The extent and depth of ameloblastic proliferation can vary considerably. ${ }^{8}$

According to Gardner the diagnosis of the unicystic type is based on 2 factors: the lesion must be clinically and radiographically uniloculated and the microscopic examination must show a single cystic lesion with a covering epithelium of ameloblastic cells. ${ }^{6}$ That is, for the lesion to be unicystic, it is necessary to consider all clinical, radiographic, and histopathologic results. However, there is a tendency for all lesions with a unicystic clinical and radiographic aspect to be considered unicystic ameloblastomas which is a mistake.

In the present case considering the age of the patient decompression followed by Enucleation was chosen as a surgical modality for the management of unicystic ameloblastoma. More aggressive primary surgery in the form of resection would basically eliminate the risk of recurrence, but this cannot be justified for unicystic ameloblastoma in view of the inevitable morbidity. A primary treatment option with minimal morbidity but which can adequately or sufficiently control the risk of recurrence is, therefore, highly desirable.

Decompression before enucleation with peripheral ostectomy is done according to the literature. ${ }^{9}$ But in the present case decompression was done every biweekly for the first one month, and then followed by enucleation with extraction of 46 and 47. Post operatively patient is asymptomatic and confirmed radiographically. A series radiographic examination was done for one year. Unicystic ameloblastoma often can be treated successfully with less aggressive surgery than that needed for multicystic amel oblastoma. ${ }^{10}$

\section{CONCLUSION:}

The prognosis for lesions of this proportion is dubious. In young patients in whom resection will result in mutilation and in small lesions that respond well to conservative treatment, recommend treatment - enucleation and curettage. ${ }^{11}$ However, in extensive lesions and the invol vement of adjacent tissues, recommends block resection. Regardless of the form of treatment, patients with unicystic Ameloblastic must be followed up for a long period to enable the early detection of possible recurrence.

\section{REFERENCES:}

1. Robinson L, Martinez MG. Unicystic ameloblastoma: a prognostic distinct entity. Cancer 1977; 40: 2278-2285

2. Vickers RA, Gorlin RJ . Ameloblastoma: delineation of early histopathol ogic features of neoplasia. Cancer 1970; 26: 699710

3. Acerkmann GL, Altini M, Shear M. The unicystic ameloblastoma: a clinicopathological study of 57 cases. J Oral Pathol 1988; 17: 541-546.

4. Dhanuthai et al. Amel oblastoma: a multicentric study. Oral Surg Oral Med Oral Pathol Oral Radiol 2012; 113:782-788

5. G. Sammartino et al. Effectiveness of a new decisional algorithm in managing mandibular amel oblastomas: A 10years experience. British J ournal of Oral and Maxillofacial Surgery 2007; 45: 306-310

6. Gardner DG. A pathologist's approach to the treatment of ameloblastoma. J Oral Maxill ofac Surg 1984; 42: 161-166.

7. Bisinelli et al. Conservative treatment of unicystic ameloblastoma. Am J Orthod Dentofacial Orthop 2010;137:396-400

8. H.P. Philipsen, P.A. Reichart. Unicystic ameloblastoma. A review of 193 cases from the literature. Oral Oncology 1998; 34: $317-325$

9. Huang et al. Surgical management of ameloblastoma in children. Oral Surg Oral Med Oral Pathol Oral Radiol Endod 2007; 104:478-485

10. Olatian and Adekeye. Unicystic ameloblastoma of the mandible: A long-term follow-up. J Oral Maxillofac Surg 1997; 55: 345-348

11. Lee et al. Unicystic amel oblastoma-use of Carnoy's solution after enucleation. Int. J . Oral Maxillofac. Surg. 2004; 33: 263-267 